\title{
Low-Cycle Fatigue of Ultrafine-Grained Aluminum at Low Temperatures*
}

\author{
Yukito Nakanishi ${ }^{1}$, Toshiyuki Fujii ${ }^{2}$, Susumu Onaka ${ }^{1}$ and Masaharu Kato ${ }^{1}$ \\ ${ }^{1}$ Department of Materials Science and Engineering, Tokyo Institute of Technology, Yokohama 226-8502, Japan \\ ${ }^{2}$ Department of Innovative and Engineered Materials, Tokyo Institute of Technology, Yokohama 226-8502, Japan
}

\begin{abstract}
Ultrafine-grained (UFG) Al of 99.98 99.99\% purity was fabricated by equal channel angular pressing. Fully reversed tensioncompression low-cycle fatigue tests were carried out under plastic strain control at various temperatures between $83 \mathrm{~K}$ and $300 \mathrm{~K}$. At $300 \mathrm{~K}$, UFG Al showed rapid cyclic softening. As test temperature decreased, cyclic softening became less significant and at $83 \mathrm{~K}$, UFG Al showed cyclic hardening till saturation. Formation of shear bands and development of dislocation structure were the characteristic features of fatigued specimens. As test temperature decreased, the area fraction of shear bands on specimen surface decreased and at $83 \mathrm{~K}$, shear bands could not be observed. In addition, local grain coarsening occurred except at $83 \mathrm{~K}$. Formation of dislocation cell and wall structures became more frequent at lower temperatures and well-developed dislocation walls were formed in grains as small as $1.5 \mu \mathrm{m}$ in size at $83 \mathrm{~K}$. [doi:10.2320/matertrans.L-MZ201103]
\end{abstract}

(Received October 1, 2010; Accepted November 16, 2010; Published March 30, 2011)

Keywords: ultrafine-grained material, equal channel angular pressing, fatigue, cyclic deformation, dislocation structure

\section{Introduction}

Fatigue behavior of ultrafine-grained (UFG) fcc metals is known to show some characteristic features such as cyclic softening, ${ }^{1-5)}$ formation of local shear bands ${ }^{2-7)}$ and local grain coarsening. ${ }^{1,2,5,8,9)}$ Though there are many studies on mechanical properties of UFG materials, the reason why UFG materials show such characteristic features has not been well understood. Using UFG $\mathrm{Cu}$, Höppel et al. ${ }^{1)}$ reported that the amount of cyclic softening and grain coarsening during cyclic deformation became less significant at $223 \mathrm{~K}$ compared to those at $293 \mathrm{~K}$. Thiele et al. ${ }^{10)}$ showed similar results using UFG Ni. Therefore, it is suggested that test temperature is an important factor to affect fatigue behavior and microstructural changes of UFG materials.

In this study, low-cycle fatigue tests were carried out under plastic strain control at various temperatures using UFG $\mathrm{Al}$ fabricated by an equal channel angular pressing (ECAP) technique. From the results of the fatigue tests as well as scanning electron microscope (SEM) and transmission electron microscope (TEM) observations, the effects of test temperature on low-cycle fatigue behavior and microstrucural changes of UFG Al will be examined.

\section{Experimental Procedure}

Pure Al (99.98 99.99\% purity) rods of $10 \mathrm{~mm}$ in diameter and $60 \mathrm{~mm}$ in length were fabricated by the ECAP technique. Each rod was subjected to 8 passes of ECAP under route $\mathrm{Bc}$ (rotation by $90^{\circ}$ in each pass). ${ }^{11)}$ After the ECAP deformation, average grain size became about $1.3 \mu \mathrm{m}$.

The fatigue specimens with the gauge length of $10 \mathrm{~mm}$ and cross-sectional area of $4 \times 6 \mathrm{~mm}^{2}$, were taken from the central part of the ECAPed rods by spark erosion in the direction parallel to the rod axis. The specimens were

*The Paper Contains Partial Overlap with the ICAA12 Proceedings by USB under the Permission of the Editorial Committee. electrolytically polished using solution of $20 \%$ perchloric acid and $80 \%$ methanol.

Fully reversed tension-compression low-cycle fatigue tests were carried out under a constant plastic strain amplitude of $\varepsilon_{\mathrm{pl}}=1 \times 10^{-3}$ at room temperature $(300 \mathrm{~K})$ and low temperatures $(198 \mathrm{~K}, 148 \mathrm{~K}, 123 \mathrm{~K}$ and $83 \mathrm{~K})$ using an electrohydraulic testing machine (Shimazu Servopet). Low temperature atmosphere was achieved using a liquid nitrogen injection apparatus. Temperature during the fatigue tests was controlled within $\pm 5 \mathrm{~K}$ by adjusting the amount of liquid nitrogen flow in the apparatus. Strain was measured with an extensometer mounted directly on the gauge section and constant strain rate of $4 \times 10^{-3} \mathrm{~s}^{-1}$ was employed using a triangular command signal. Fatigue tests were interrupted when cumulative plastic strain $\varepsilon_{\text {cum }}$ defined as

$$
\varepsilon_{\mathrm{cum}}=4 N \varepsilon_{\mathrm{pl}}
$$

reached 10, where $N$ is the number of deformation cycles and $\varepsilon_{\mathrm{pl}}=1 \times 10^{-3}$. After the fatigue tests, specimen surfaces were observed by using a JEOL 5310 SEM.

The fatigued specimens were sliced into $3 \mathrm{~mm}$ diameter disks and ground down to a thickness of $0.2 \mathrm{~mm}$ using silicon-carbide paper. Then, the samples were electrolytically polished using a twin-jet polisher (Struers Tenupol-5) in solution of $8 \%$ perchloric acid, $10 \%$ 2-butoxyethanol and $82 \%$ methanol. Microstructure observations were performed by using a JEOL 2011 TEM at an acceleration voltage of $200 \mathrm{kV}$.

\section{Results and Discussion}

\subsection{Cyclic hardening and softening}

Figure 1 shows cyclic hardening/softening curves of UFG $\mathrm{Al}$ at various temperatures. ${ }^{12)}$ At $300 \mathrm{~K}$, UFG Al shows hardening followed by rapid cyclic softening. Since macroscopically-visible cracks were formed on the specimen surface, the fatigue test at $300 \mathrm{~K}$ was stopped well before cumulative plastic strain reached $\varepsilon_{\text {cum }}=10$. It can be seen from Fig. 1 that as test temperature decreases, stress 
amplitude becomes larger and cyclic softening becomes less significant. At $83 \mathrm{~K}$, UFG Al shows slight hardening followed by near saturation, i.e., stress amplitude $\sigma_{\mathrm{a}}=155$ $\mathrm{MPa}$ does not change much with increase in fatigue cycles after $\varepsilon_{\text {cum }} \approx 1$.

\subsection{Shear band formation}

Figures 2(a) to (e) show a series of SEM images taken

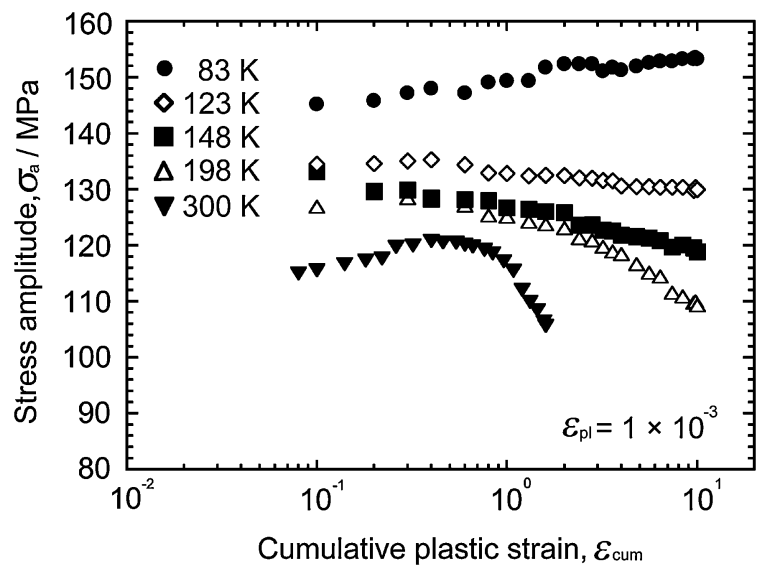

Fig. 1 Cyclic hardening/softening curves of UFG Al fatigued under constant plastic strain amplitude $\varepsilon_{\mathrm{pl}}=1 \times 10^{-3}$ at various temperatures. $^{12)}$ from specimens fatigued at various temperatures. Shear bands composed of intrusions and extrusions were formed on the surface of specimens. As can be seen, these shear bands extend over much larger distances than the average grain size of about $1.3 \mu \mathrm{m}$. In the past work, ${ }^{4,5)}$ it was found that strain localization occurred in the shear bands during cyclic deformation and micro-cracks initiated along the shear bands. Similarly, micro-cracks are observed along the shear bands in the present study, as shown by the arrow in Fig. 2(a). The area fraction and the length of shear bands decrease as test temperature decreases (Figs. 2(b) to (e)). At $83 \mathrm{~K}$, shear bands could not be detected on the specimen surface. Since the amount of cyclic softening becomes less as the fraction of shear bands decreases, the formation of shear bands is considered to contribute to the cyclic softening of UFG Al.

\subsection{Microstructural observation}

The microstructures of an as-ECAPed specimen and a specimen fatigued at $300 \mathrm{~K}$ are shown in Figs. 3(a) and (b). Comparison of Fig. 3(a) with (b) reveals that grain growth has occurred to some extent even when the fatigue test was forced to be interrupted well before $\varepsilon_{\text {cum }}$ reached 10 (See Fig. 1). On the other hand, no distinct dislocation substructure can be seen even in larger grains.

When test temperature decreases, microstructural changes during cyclic deformation become more noticeable, as shown
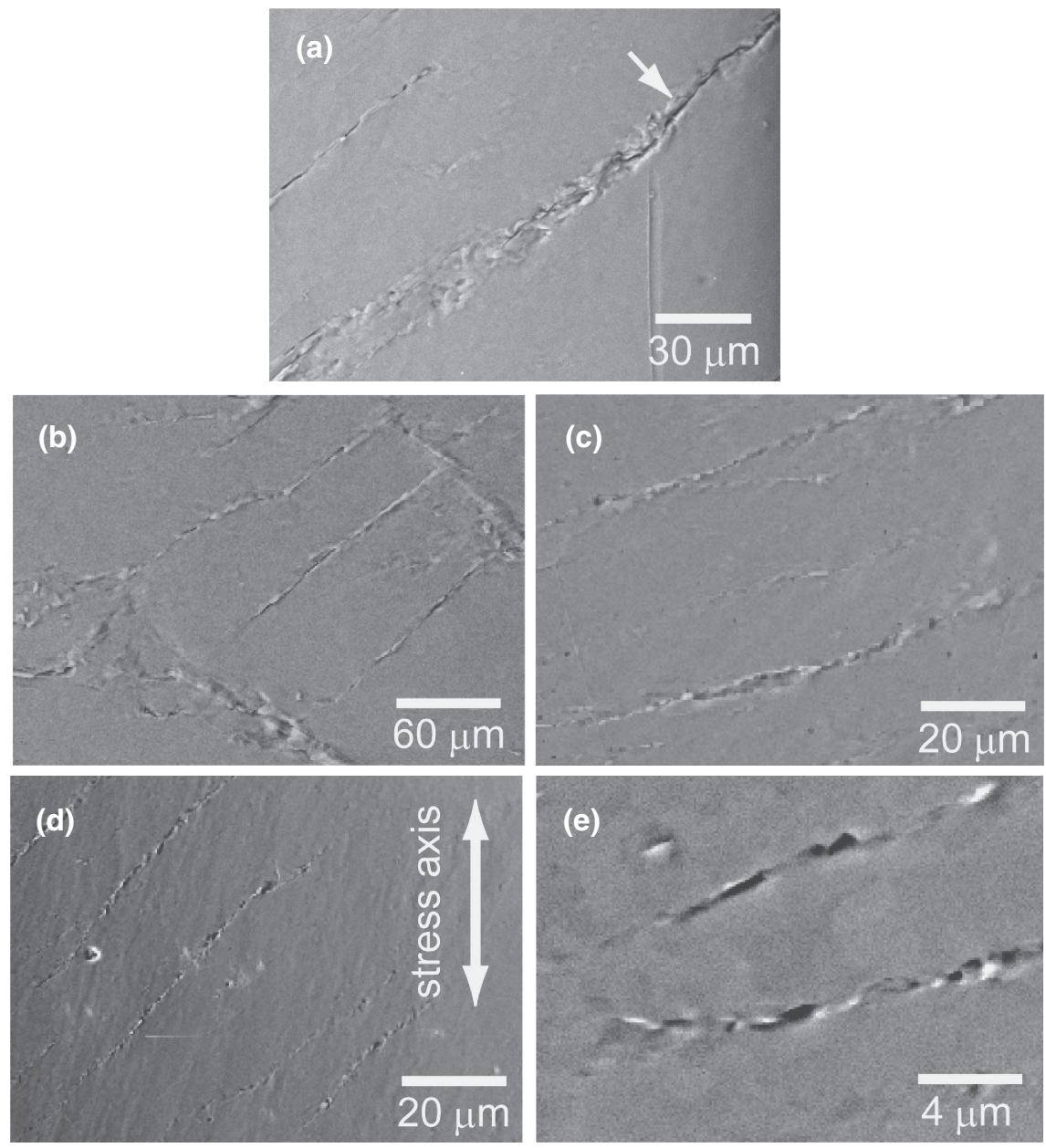

Fig. 2 SEM images of micro-cracks and shear bands on the surface of specimens fatigued at (a) $300 \mathrm{~K}$ (The arrow shows a micro-crack),

(b) $300 \mathrm{~K}$, (c) $198 \mathrm{~K}$, (d) $148 \mathrm{~K}$ and (e) $123 \mathrm{~K}$. Note the different magnifications for these photographs. 

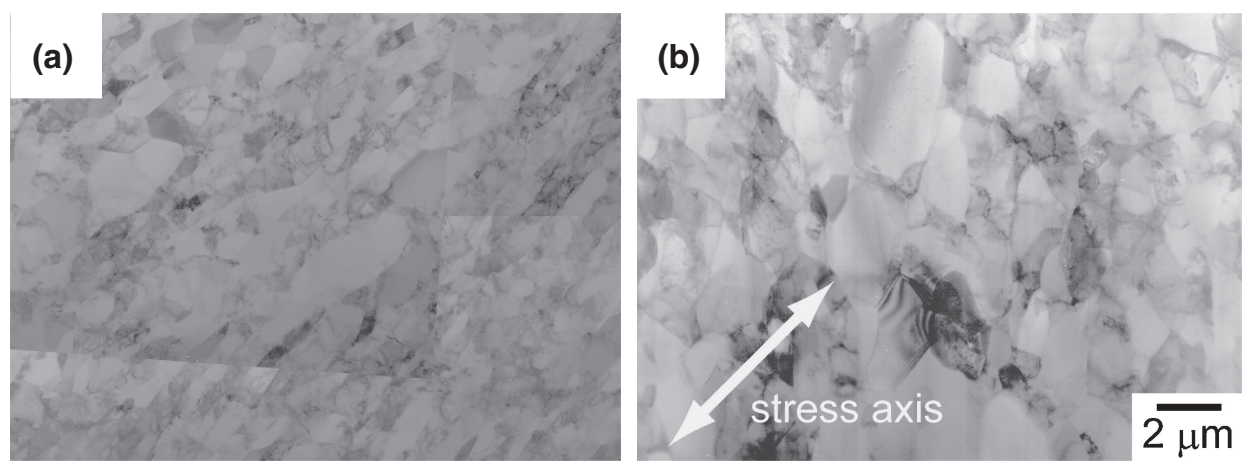

Fig. 3 TEM photographs of UFG Al: (a) as-ECAPed specimen, (b) fatigued specimen at $300 \mathrm{~K}$. Stress axis inclines nearly $45^{\circ}$ to the vertical direction.

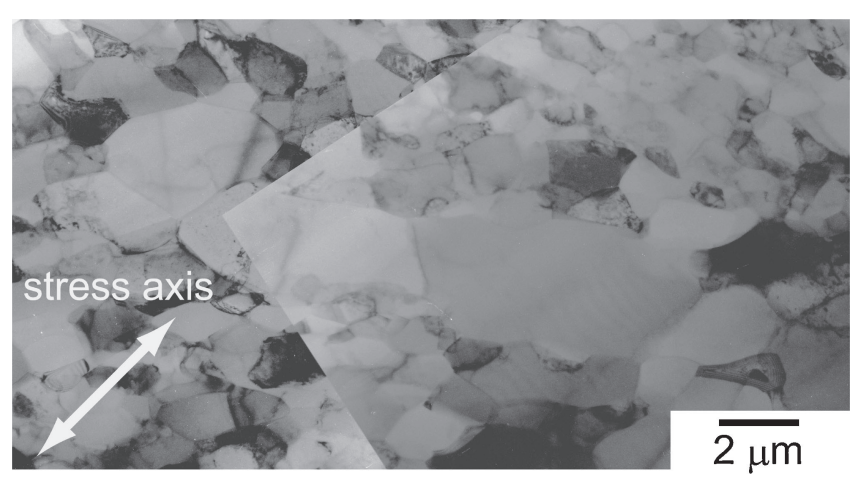

Fig. 4 Occurrence of local grain coarsening in a specimen fatigued at $198 \mathrm{~K}$.

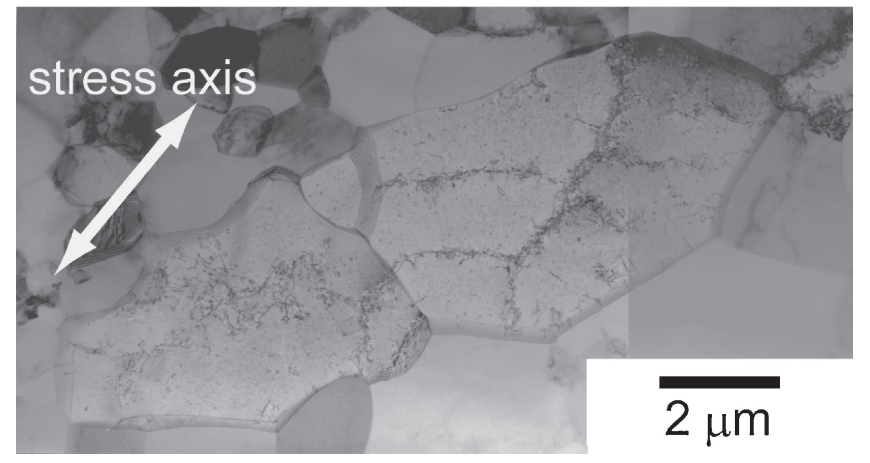

Fig. 5 Cell structure formed in coarsened grains of a specimen fatigued at $198 \mathrm{~K}$.
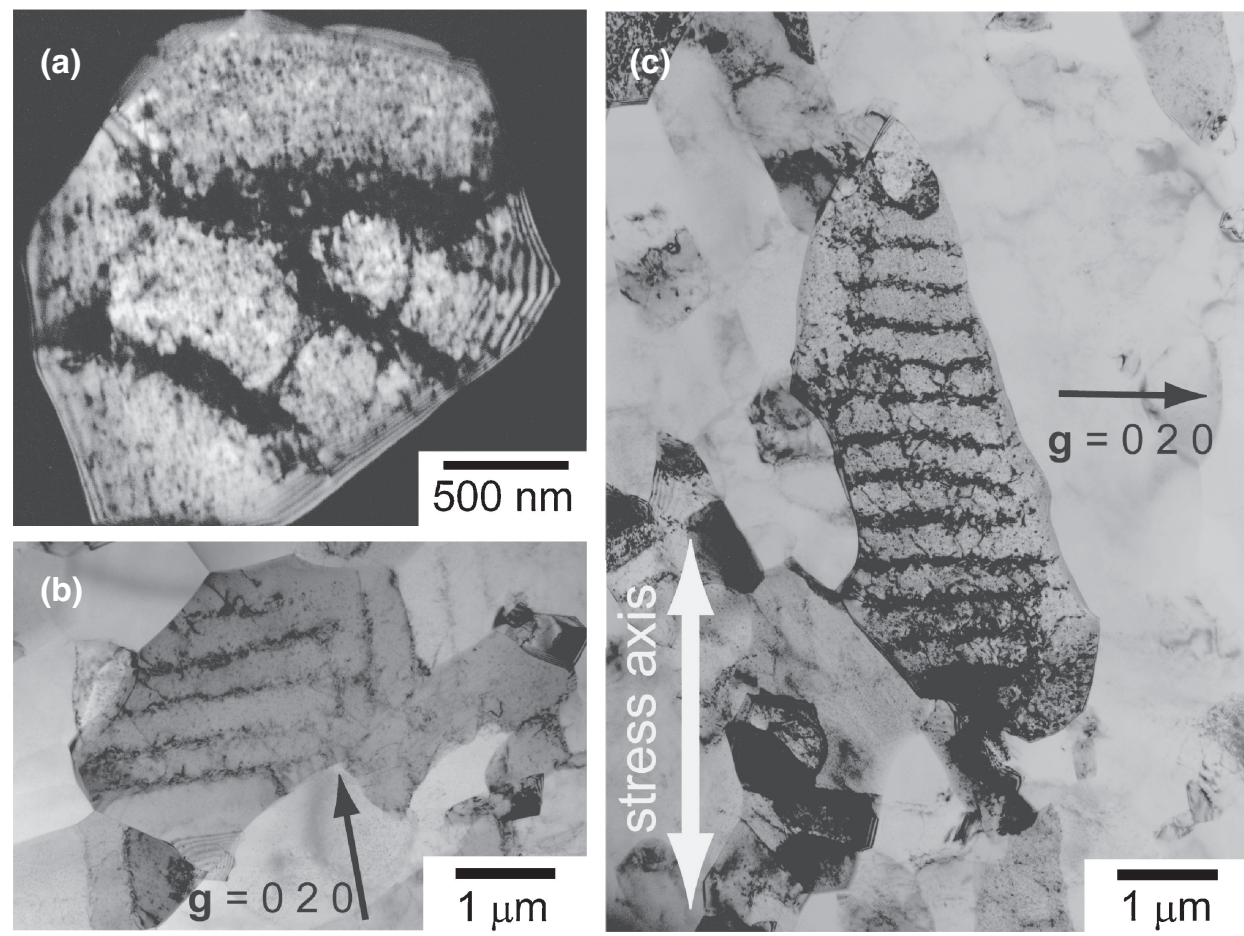

Fig. 6 Dislocation cell (a) and wall ((b) and (c)) structures formed in fine grains of a specimen fatigued at $83 \mathrm{~K}$.

in Fig. 4 to 7. At $198 \mathrm{~K}$, in addition to local grain coarsening (Fig. 4), cell structure was formed in some coarsened grains (Fig. 5). As test temperature decreases, the fraction of coarsened grains decreases and dislocation structures are formed even in smaller grains. For example at $83 \mathrm{~K}$, primitive dislocation walls were formed in grains as small as $1.5 \mu \mathrm{m}$ (Fig. 6(a)) and well-developed dislocation walls were formed in larger grains (Figs. 6(b) and (c)). Moreover, the fraction of 


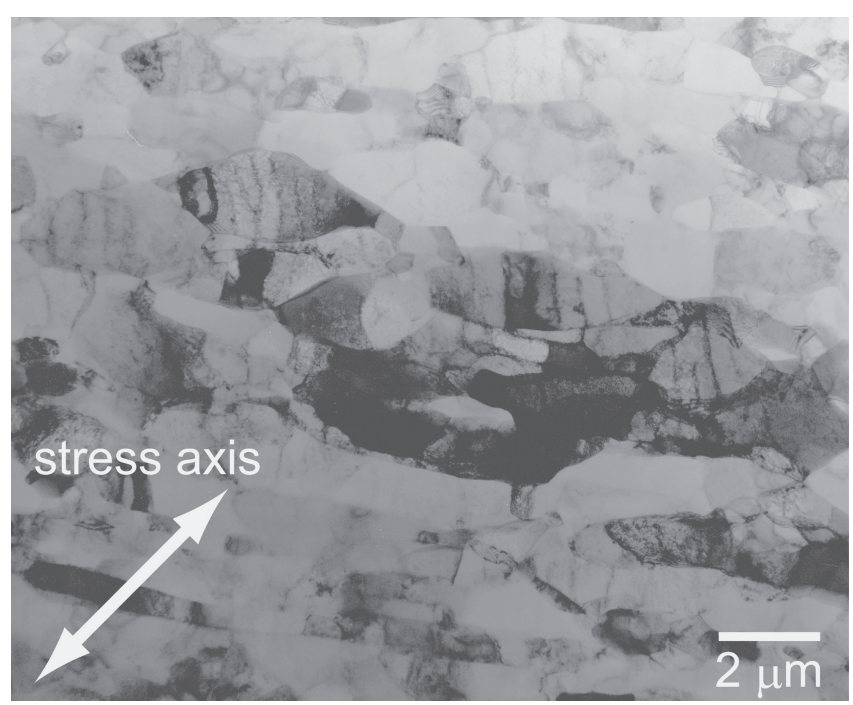

Fig. 7 TEM photograph of UFG Al fatigued at $83 \mathrm{~K}$. The fraction of grains that contain dislocation wall structure is about $60 \%$.

the grains that contain cell and wall structures increases as test temperature decreases. For example, Fig. 7 shows that the fraction is nearly $60 \%$ when fatigued at $83 \mathrm{~K}$.

Average wall-to-wall spacing is about $300 \mathrm{~nm}$ and this value is much less than the frequently observed values between 1 to $4 \mu \mathrm{m}$ in single-crystalline and coarse-grained Al. ${ }^{13-16)}$ As shown in Figs. 6(b) and (c), the dislocation walls appear to align parallel to the $\left\{\begin{array}{lll}1 & 0 & 0\end{array}\right\}$ plane just like those formed in single-crystalline and coarse-grained Al. ${ }^{13-17)}$ It is known that the multiple slip is responsible for the formation of the $\{100\}$ walls and labyrinth structure in fcc metals. ${ }^{15,18)}$ It is very probable that such multiple slip (or the interaction between different slip systems) occurs very frequently in highly constrained grains of UFG materials. Therefore, we believe that the wall structures in Figs. 6(b) and (c) were formed in the same manner as those formed in singlecrystalline and coarse-grained $\mathrm{Al}$, with only difference being the much smaller wall-to-wall spacing. As far as the authors know, this is the first observation of cell and wall structures in UFG Al after cyclic deformation. From the above experimental results, we conclude that well-developed dislocation structures are formed only at low enough temperatures in UFG Al.

\subsection{Relationship between dislocation wall spacing and stress amplitude}

In the present study, well-developed dislocation walls were observed at $83 \mathrm{~K}$. We have found that the average wall spacing of UFG Al was much smaller than that of singlecrystalline and coarse-grained $\mathrm{Al} .^{13-16)}$ Generally, the relationship between dislocation wall-to-wall spacing $d$ on the stress amplitude $\sigma_{\mathrm{a}}$ is described as: ${ }^{19)}$

$$
\sigma_{\mathrm{a}}=\alpha \mu b / d
$$

where $\alpha$ is a dimensionless constant, $\mu$ the shear modulus and $b$ the magnitude of the Burgers vector. For the case of the socalled ladder structure in persistent slip bands, ${ }^{20)}$ dislocation walls are formed parallel to $\{110\}$. On the other hand, $\{100\}$ walls were observed in the present study. Nevertheless, we

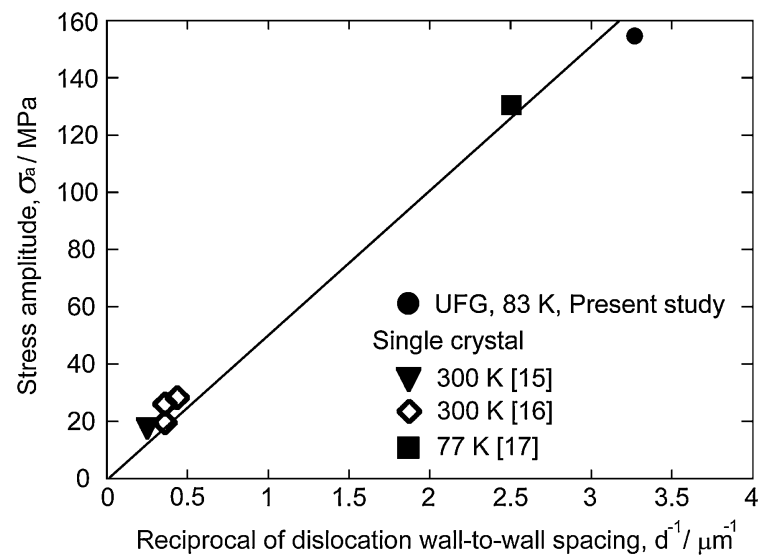

Fig. 8 Relationship between saturation stress amplitude and reciprocal of dislocation wall-to-wall spacing. Experimental data for Al single crystals $^{15-17)}$ and UFG Al are shown.

consider that the relationship of eq. (2) holds, at least as a first approximation, equally for $\{100\}$ and $\{110\}$ walls. With the experimental results of UFG $\mathrm{Al}$ fatigued at $83 \mathrm{~K}$, i.e., $\sigma_{\mathrm{a}}=155 \mathrm{MPa}, d=300 \mathrm{~nm}$ together with $\mu=27 \mathrm{GPa}$ and $b=0.29 \mathrm{~nm}$, we obtain $\alpha=5.9$ from eq. (2). This value of $\alpha$ is in good agreement with theoretically estimated ones, between 4 and $6 .^{21-23)}$

Figure 8 summarizes the experimental results of the inverse dislocation wall spacing under a given stress amplitude for single-crystalline $\mathrm{Al}^{15-17)}$ and UFG $\mathrm{Al}$ in this study. As can be seen, all the data points lie on a single straight line. From the slope of the straight line, we find $\alpha=6.4$ which is again reasonable. Therefore, we believe that the formation mechanism of the dislocation walls in UFG Al is essentially the same as that in single-crystalline Al.

\section{Concluding Remarks}

The low-cycle fatigue behavior of UFG Al was investigated under plastic strain control at various temperatures between $83 \mathrm{~K}$ and $300 \mathrm{~K}$. We have found that test temperature plays an important role on the fatigue behavior and formation of dislocation structures. We have found that as test temperature decreases,

(1) Cyclic softening becomes less significant.

(2) Fraction of shear bands decreases.

(3) Fraction of coarsened grains decreases.

(4) Formation of dislocation cell and wall structures becomes easier.

From the above results, we conclude that shear band formation, development of dislocation structure and grain coarsening are the three important factors to characterize the low-temperature fatigue behavior of UFG Al. Indeed, these three factors can be mutually related to each other. For example, one may think that dislocation structures are formed preferentially at shear band regions with concentrated plastic deformation. If this is the case, however, dislocation structures must have developed more easily at higher temperatures where shear bands appear more frequently. Instead, we have seen that the experimental results are the opposite. Therefore, the present study indicates that high 
enough stresses are necessary for fine cell and wall structures to be formed in small grains of fatigued UFG Al. However, the relationship between the shear-band formation and grain coarsening, for example, is yet to be revealed. To understand the mechanism of fatigue and cyclic deformation behavior of UFG materials is, thus, a challenging research subject and the present study provides important experimental results for future studies.

\section{Acknowledgments}

This study was supported by a Grant-in-Aid for Scientific Research on Innovative Area, "Bulk Nanostructured Metals" through MEXT, Japan (contract No. 22102006). The authors also acknowledge Professors Zenji Horita (Kyushu University), Hisashi Sato and Yoshimi Watanabe (Nagoya Institute of Technology) for fabricating UFG Al and Professor Yoji Miyajima (Tokyo Institute of Technology) for fruitful discussion.

\section{REFERENCES}

1) H. W. Höppel, Z. Zhou, H. Mughrabi and R. Z. Valiev: Philos. Mag. A 82 (2002) 1781-1794.

2) S. R. Agnew and J. R. Weertman: Mater. Sci. Eng. A 244 (1998) 145153.

3) L. Kunz, P. Lukáš and M. Svoboda: Mater. Sci. Eng. A 424 (2006) 97104

4) C. Xu, Q. Wang, M. Zheng, J. Li, M. Huang, Q. Jia, J. Zhu, L. Kunz and M. Buksa: Mater. Sci. Eng. A 475 (2008) 249-256.

5) Y. Furukawa, T. Fujii, S. Onaka and M. Kato: Mater. Trans. 50 (2009) $70-75$

6) S. D. Wu, Z. G. Wang, C. B. Jiang, G. Y. Li, I. V. Alexandrov and R. Z.
Valiev: Scr. Mater. 48 (2003) 1605-1609.

7) M. Goto, S. Z. Han, T. Yakushiji, C. Y. Lim and S. S. Kim: Scr. Mater. 54 (2006) 2101-2106

8) H. Mughrabi and H. W. Höppel: Mat. Res. Sym. Proc. 634 (Erlangen, 2001) B2.2.1-B2.2.11.

9) H. W. Höppel, M. Brunnbauer, H. Mughrabi, R. Z. Valiev and A. P. Zhilyaev: Proc. Materials Week 2000, (Wiley-VCH, 2001) http:// www.materialsweek.org/ proceedings.

10) E. Thiele, J. Bretschneider, L. Hollang, N. Schell and C. Holste: Investigations and Applications of Severe Plastic Deformation, (Kluwer Academic Publishers, 2000) pp. 173-178.

11) Y. Iwahashi, Z. Horita, M. Nemoto and T. G. Langdon: Acta Mater. 46 (1998) 3317-3331

12) Y. Nakanishi, T. Fujii, S. Onaka and M. Kato: Proc. 12th Int. Conf. on Aluminium Alloys, ed. by S. Kumai, O. Umezawa, Y. Takayama, T. Tsuchida and T. Sato, (The Japan Inst. Light Metals, 2010) pp. 326331.

13) P. Charsley and L. J. Harris: Scr. Metall. 21 (1987) 341-344.

14) P. Charsley, U. Bangert and L. J. Appleby: Mater. Sci. Eng. A 113 (1989) 231-236.

15) M. Videm and N. Ryum: Mater. Sci. Eng. A 219 (1996) 1-10.

16) T. Fujii, S. Uju, H. Tanaka, T. Murayama, C. Watanabe, S. Onaka and M. Kato: Plasticity, Failure and Fatigue in Structural Materials from Macro to Nano: Proc. Hael Mughrabi Honorary Symposium, Ed. by K. J. Hsia, M. Göken, T. Pollock, P. D. Portella and N. R. Moody, (The Minerals, Metals \& Material Society, 2008) pp. 123-127.

17) T. Fujii: Proc. 12th Int. Conf. on Aluminium Alloys, ed. by S. Kumai, O. Umezawa, Y. Takayama, T. Tsuchida and T. Sato, (The Japan Inst. Light Metals, 2010) 322-325.

18) P. Li, S. X. Li, Z. G. Wang and Z. F. Zhang: Acta Mater. 58 (2010) 3281-3294.

19) Z. S. Basinski, A. S. Korbel and S. J. Basinski: Acta Metall. 28 (1980) 191-207.

20) P. J. Wood: Phil. Mag. 28 (1973) 155-191.

21) O. B. Pedersen: Acta Metall. 38 (1990) 1221-1239.

22) L. M. Brown: Metall. Trans. A 22 (1991) 1693-1708.

23) L. M. Brown: Mater. Sci. Eng. A 285 (2000) 35-42. 